\title{
A PARAMETRIC ANALYSIS FOR THE DAFALIAS-KALIAKIN BOUNDING SURFACE VISCOPLASTIC MODEL BASED ON THE DIFLUPRESS L.D. TEST
}

\author{
C. LEIDWANGER-RABIS, R. CHAMBON \\ Soils, Solids, Structures Laboratory, \\ BP. 53 X, 38041 Grenoble Cedex \\ France \\ P. CATEL \\ Department T.E.G.G, Electricité de France, \\ 905 avenue du Camp de Menthe, \\ BP. 605, 13093 Aix-en-Provence, Cedex 2 \\ France \\ R. CHARLIER, X.L. LI \\ Department MSM \\ University of Liege, \\ 6, quai Banning, 4000 Liege \\ Belgium
}

\begin{abstract}
In order to predict delayed settlements of heavy structures, the authors decided to use the elasto-viscoplastic model of Dafalias-Kaliakin. To idemify the parameters of the constitutive equations, they use above all the data of a new in-situ test, the Diflupress L.D. designed to approach the creep behavior of soil. In a first section, the principle of the model is presented. Then, the important parameters of the model are identified, mostly from in-situ test data since the laboratory tests data are not numerous and reliable. Finally, a study of sensitivity on the parameters which influence the viscoplastic response of the model is made.
\end{abstract}

\section{INTRODUCTION}

It is usually rather difficult to predict the long term behavior of heavy structures from laboratory test data. In that way, it is interesting to have in-situ tests which are more representative of the real state of soil. The problems of remoulding or no realistic tests are less important with in-situ tests than with laboratory tests. Furthermore, in order to approach the delayed behavior of soils, creep tests are recommended. For these reasons, Electricité de France was prompted to attempt a new in-situ approach to creep testing based on the pressuremeter: the Diflupress L.D. (see reference [1] to [3]) 
The purpose of our research concerns the use of in-situ data in constitutive equations in order to perform a prediction calculation of long term behavior of heavy structures. This work can be shared in two parts. The first one concerns the parameters identification of constitutive equations. The second one relates to the calculation of delayed settlements by using constitutive equations, the set of parameters identified from the first step and the boundary conditions of the problem. This paper only deals with the parameters identification of constitutive equations. So we present here the use of in-situ tests data to identify the parameters of a tridimensional model of behavior which considers a viscous part of the behavior.

The in-situ tests performed with the Diffupress L.D. on nuclear plants sites which present notable delayed settlements give us the opportunity for validating our work. Some authors already used in-situ tests data performed with the pressuremeter in order to identify the parameters of an elastoplastic model of behavior [4]. They also used the Diflupress L.D. tests data to identify the parameters of an unidimensional non-linear viscoelastic constitutive equations [5].

The identification of parameters from in-situ measurements is currently made from inverse equations [6]. This supposes the equations are not too complicated. However, the identified parameters are those of elastic linear or non-linear models $[7,8]$. On the problem of predicting long term behavior of heavy structures, one can quote works made on consolidation problems. The consolidation equations are inversed and in-situ measurements are used to identify the parameters of elastic linear [9] and non linear models of behavior [10]. This paper presents the first attempt at using in-situ creep tests data obtained from the Diflupress L.D. test to identify the parameters of an elasto-viscoplastic model. Once the parameters identified, a modelling of the behavior of heavy structures is planned. The results $[3,11]$ are not detailed in this paper but the most interesting data are presented in the conclusion.

The clayey materials encountered and the notable delayed settlement observed on the nuclear plant sites induced the use of the Dafalias-Kaliakin constitutive equations. This model is an extension of the Cam-Clay model. The plastic limit surface is replaced by a bounding surface and a viscous component of the response is added to predict behavior due to viscosity of clays. The important points of the model will be presented in the first part of the paper for the understanding of the different parameters.

Several elastoplastic parameters, such as $\lambda, \kappa, G$ or $\nu, M_{c}$ and $p_{c}$ the preconsolidation pressure, are parameters similar to the ones needed by the Cam-Clay model. They are determined from laboratory tests data. The other elastoplastic parameters and the viscoplastic parameters should be identified from laboratory tests. The identification is made difficult by the coupling between the elastoplastic and the viscoplastic responses. It is important to notice that some difficulties were encountered in the identification of the different parameters as we used 
laboratory tests already performed. Indeed, it was impossible to perform supplementary laboratory tests to confirm the conclusions made from the tests already performed before we began our work. So the choice was made to identify the elastoplastic and viscoplastic parameters by the in-situ tests data in spite of the difficulties encountered. The identification procedure of the different parameters and the difficulties encountered are presented in the second part of the paper. Finally, in the third part, a study of sensitivity is made around this set of parameters, especially around the viscoplastic parameters. In order to model the long term behavior of soil, it is worthwhile insisting on the viscoplastic parameters.

\section{NTRODUCTION TO THE DAFALIASKALIAKIN BOUNDNG SURFACE MODEL FOR COHESIVE SOILS}

The DAFALIAS-KALIAKIN Bounding Surface Model is an elastoplastic-viscoplastic model for isotropic cohesive soils. It has been developed by DAFALIAS and KALIAKIN. The details regarding the model have been presented by themselves $[12,13,14,15,16]$. Here, only a brief summary is presented.

This model is developed on the basis of the concept of the bounding surface in stress space and within the framework of critical state soil mechanics. The following points are the prominent features of this model:

- the outstanding advantage of the bounding surface concept is that the inelastic deformations can occur for stress points within the bounding surface

- this model considers time related behavior of soils

- coupling between plasticity and viscoplasticity is included in this model even for stress points within the bounding surface

- it can simulate the behavior of overconsolidated cohesive soils (softening)

\section{The Bounding Surface Concept}

In classical theory of yield surface plasticity or viscoplasticity, the inelastic deformations can occur only for stress points lying on a yield surface (elastoplasticity hypothesis) and those outside this surface (elasto-viscoplasticity) [17]. However, experimental results show that the instantaneous (elastoplastic) and delayed (viscoplastic) deformations occur simultaneously. Thus, the notion of bounding surface instead of yield surface was introduced by DAFALIAS.

The material state is defined in terms of the stress tensor $\sigma_{i j}$ and proper inelastic internal 
variables $q_{n}$ ( $n$ denotes the plurality of $q_{n}$ ). At any moment, a bounding surface $F$ can be analytically defined in stress space. To each actual stress point $\sigma_{i j}$ lying within or on the surface, a unique image stress point $\bar{\sigma}_{\mathrm{ij}}$ can be obtained by projecting the actual stress point $\sigma_{\mathrm{ij}}$ onto the surface with a radial mapping rule (Figure 1 ).

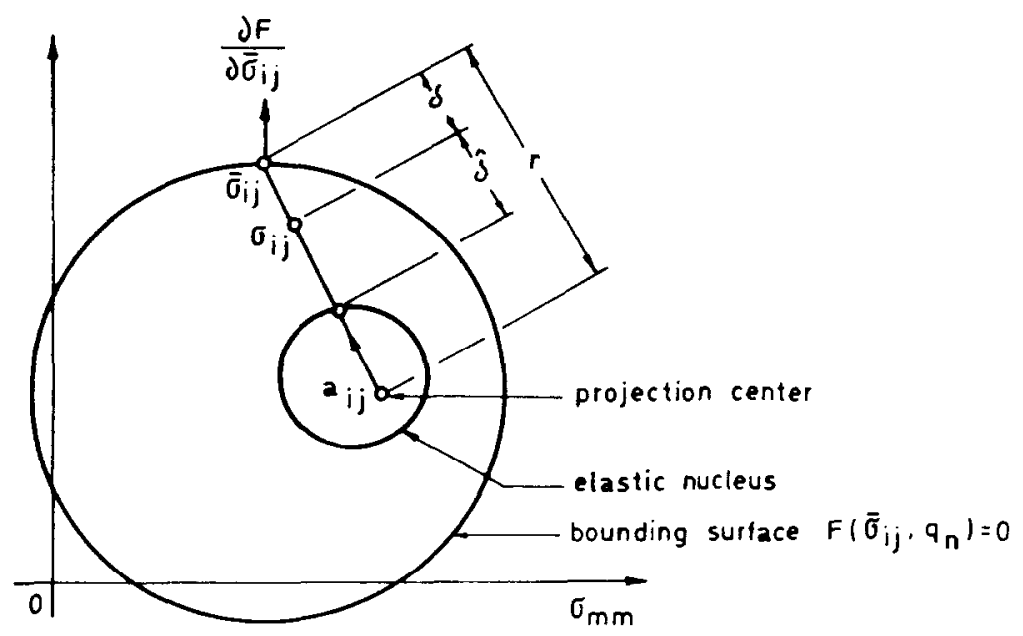

\section{FIGURE 1}

The bounding surface is then analytically written as :

$F\left(\bar{\sigma}_{i j}, q_{n}\right)=0$

The distance $\delta$ between $\sigma_{\mathrm{ij}}$ and $\bar{\sigma}_{\mathrm{ij}}$ serves to determine the relation between the plastic modulus $\mathrm{K}_{\mathrm{p}}$ (associated with $\sigma_{\mathrm{ij}}$ ) and the bounding plastic modulus $\overline{\mathrm{K}}_{\mathrm{p}}$ (associated with $\bar{\sigma}_{i \mathrm{j}}$ ). $K_{p}$ and $\overline{\mathbf{K}}_{\mathrm{p}}$ are used to calculate the inelastic deformations. Thus, inelastic states are not restricted only to stress points lying on the surface. This is, in fact, the essence of the bounding surface concept.

The radial mapping rule is :

$\bar{\sigma}_{\mathrm{ij}}=b\left(\sigma_{\mathrm{ij}}-\mathbf{a}_{\mathrm{ij}}\right)+a_{\mathrm{ij}}$

where $a_{i j}$ is the projection center. $b(b \geq 1)$ depends on the internal variables. 
The direction of inelastic loading-unloading is defined as the gradient of $F$ at $\bar{\sigma}_{\mathrm{ij}}$.

In fact, the plastic deformation (coupled with viscous deformation) is obtained by :

$$
\dot{\varepsilon}_{\mathrm{ij}}^{\mathrm{p}}=\langle\mathrm{L}\rangle \frac{\partial \mathrm{F}}{\partial \bar{\sigma}_{\mathrm{ij}}}
$$

where $L$ is strongly dependent on the plastic modulus $K_{p}$ determined by :

$$
\mathbf{K}_{p}=\overline{\mathbf{K}}_{\mathrm{p}}+\hat{\mathbf{H}} \frac{\delta}{\left\langle r-S_{p} \delta\right\rangle}
$$

where: $\quad-\overline{\mathbf{K}}_{\mathrm{p}}$ can be deduced from the consistency condition $\dot{\mathbf{F}}=0$

- $\hat{\mathbf{H}}$ denotes a proper scalar hardening function.

$-r$ is the distance between $a_{i j}$ and $\bar{\sigma}_{i j}$

$-\delta$ is the distance between $\sigma_{i j}$ and $\bar{\sigma}_{i j}$

- both $\mathrm{r}$ and $\delta$ can be calculated easily in the stress space I-J (I: the first effective stress invariant ; $J$ : the square root of the second deviatoric stress invariant)

- $S_{p}$ is a parameter of the model, it defines an elastic nucleus (Fig. 1).

To have an insight into the role of the bounding surface concept and the notion of the elastic nucleus, we can analyse the equation (4).

If $\delta=0, \sigma_{\| j}$ coincides with $\bar{\sigma}_{i j}$, we have $K_{p}=\bar{K}_{p}$.

If $0<\delta<r / S_{p}$ and $\hat{H}$ is not approaching infinity, we have $K_{p}>\bar{K}_{p}$ (with $K_{p} \rightarrow \infty$ as $\left.\delta \rightarrow r / S_{p}\right)$.

If $\delta \geq r / S_{p}, K_{p}$ becomes infinite and, therefore, a purely elastic domain around the projection center $a_{\mathrm{ij}}$ is defined. We call this domain the "elastic mucleus". That is to say, when the stress points enter into the elastic mucleus $\left(\delta \geq r / S_{p}\right)$, there are not any inelastic deformations.

\section{The Formulation of the Model}

Here we give only a brief summary of the formulation used for isotropic cohesive soils (which has been implemented in our Finite Element code LAGAMINE [18]).

The material state is defined by the effective stress $\sigma_{i j}$ and a single internal variable $e^{i}$ (inelastic void ratio) which measures the inelastic change in volumetric strain. 
The effective stress $\sigma_{\mathrm{ij}}$ is related to the total stress $\sigma_{\mathrm{ij}}^{\mathrm{t}}$ and to the pore fluid pressure u by: $\sigma_{\mathrm{ij}}^{\mathrm{t}}=\sigma_{\ddot{\mathrm{j}}}+\delta_{\mathrm{ij}} \mathrm{u}$

The model is developed in the space of stress invariants $I$ and $J$, and the "Lode" angle $\alpha$. These invariants are given by :

$I=\sigma_{k \mathbf{k}}=\sigma_{11}+\sigma_{22}+\sigma_{33}$

$J=\sqrt{\frac{1}{2} S_{i j} S_{i j}}$ with $S_{i j}=\sigma_{i j}-\frac{1}{3} I \delta_{i j}$

$\alpha=\frac{1}{3} \sin ^{-1}\left[\frac{3 \sqrt{3}}{2}\left(\frac{S}{J}\right)^{3}\right]$ with $-\frac{\pi}{6} \leq \alpha \leq \frac{\pi}{6}$

where : $S=\left(\frac{1}{3} S_{i j} S_{j k} S_{k i}\right)^{\frac{1}{3}}$

The bounding surface is therefore defined by :

$\mathbf{F}\left(\overline{\mathbf{I}}, \overline{\mathbf{J}}, \alpha, \mathbf{e}^{\mathrm{i}}\right)=0$

Figure 2 shows a meridian section of the surface (i.e., for a given value of $\alpha$ ).

The bounding surface is composed of two ellipses and one hyperbola; the equations of which will not be presented here (see reference $[12,19]$ ). In the deviatoric plane, the bounding surface is depending on the Lode angle, allowing to define accurstely the friction angle on triaxial compression and extension stress paths.

In equation (5), $\overline{\mathrm{I}}, \overline{\mathrm{J}}$ refer to stress states on the bounding surface and are related to the actual stress states I, $\mathrm{J}$ by the radial mapping rule :

$\overline{\mathrm{I}}=\mathrm{b}\left(\mathrm{I}-\mathrm{CI}_{\mathrm{o}}\right)+\mathrm{CI}_{\mathrm{o}}$

$\overline{\mathrm{S}}_{\mathrm{ij}}=\mathrm{bS}_{\mathrm{ij}} \rightarrow \overline{\mathrm{J}}=\mathrm{bJ}, \bar{\alpha}=\alpha, \overline{\mathrm{S}}=\mathrm{bS}$

The value of $b(b \geq 1)$ is deduced by substituting $\bar{I}$ and $\bar{J}$ from equations (6.1.) and (6.2.) into equation ( 5 ) and solving for $b$. $I_{0}$ denotes the intersection of the bounding surface with the positive $\mathrm{I}$ - axis and is a measure of the preconsolidation history of the soil. $\mathbf{C}(0 \leq \mathrm{C}<1)$ is a material constant. 


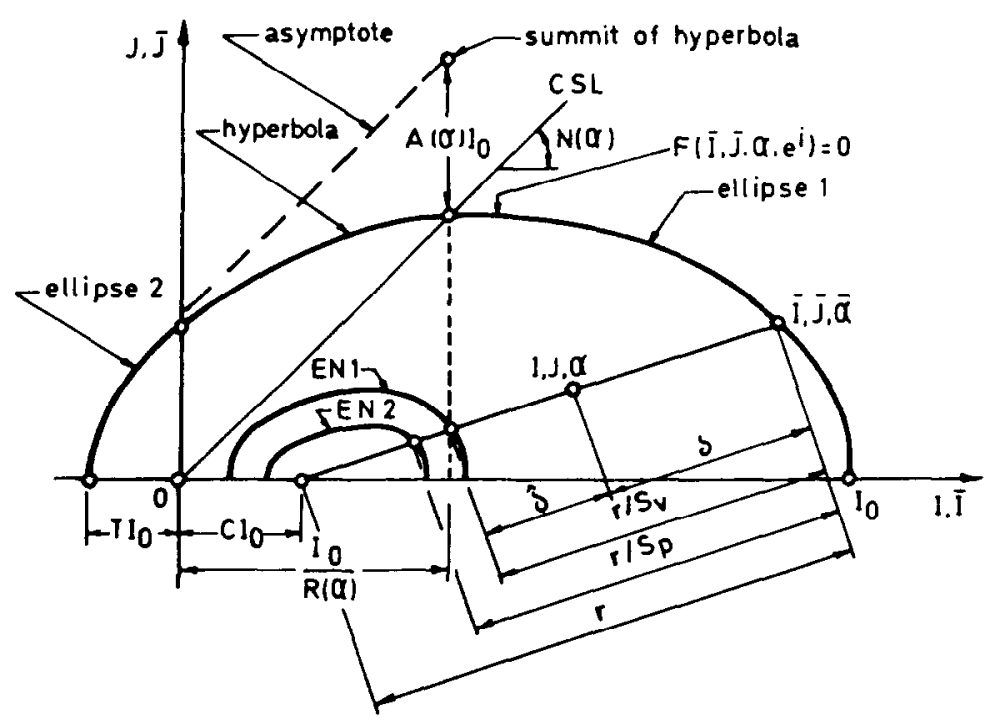

FIGURE 2 - Schematic illustration of the radial mapping rule of the bounding surface in stress invariants space

\section{The Response of the Model}

In the model, the total strain rate is additively decomposed into an elastic and an inelastic part, the later consisting of a delayed (viscoplastic) and an instantaneous (plastic) part. It follows that :

$\dot{\varepsilon}_{\mathrm{ij}}=\dot{\varepsilon}_{\mathrm{ij}}^{\mathrm{e}}+\dot{\varepsilon}_{\mathrm{ij}}^{\mathrm{p}}+\dot{\varepsilon}_{\mathrm{ij}}^{\mathrm{y}}$

In the same way, the internal variable $e^{i}$ is also decomposed into two parts: a delayed and an instantaneous parts :

$\dot{\mathbf{e}}^{\mathrm{i}}=\dot{\mathbf{e}}^{\mathrm{p}}+\dot{\mathbf{e}}^{v}$

Each part of the total response will be illustrated briefly below:

The elastic response 
The elastic strain rate is given by :

$\dot{\varepsilon}_{\mathrm{ij}}^{\mathrm{e}}=\mathbf{C}_{\mathrm{ijkl}} \dot{\sigma}_{\mathbf{k d}}$

and

$C_{\mathrm{ijkl}}=\frac{2 \mathrm{G}-3 \mathrm{~K}}{18 \mathrm{KG}} \delta_{\mathrm{ij}} \delta_{\mathrm{kl}}+\frac{1}{2 \mathrm{G}} \delta_{\mathrm{ik}} \delta_{\mathrm{jl}}$

in which the elastic bulk modulus is defined in the following manner

$\mathbf{K}=\frac{1+\mathbf{e}_{\text {in }}}{3 \kappa}\left(\left\langle I-I_{1}\right\rangle+I_{1}\right)$

The elastic shear moduhus $\mathrm{G}$ is calculated from $\mathrm{K}$ and a constant $\nu$ (Poisson's ratio). The elastic response is non-linear.

\section{The viscoplastic response}

To determine the viscoplastic response, another similar elastic nucleus was defined in association with $\dot{\varepsilon}_{\mathrm{ij}}^{\mathrm{v}}$ (Fig. 2). This requires the introduction of another parameter $S_{v}$ in the formulation. The viscoplastic rate equation is based upon the elastic/viscoplastic theory of PERZYNA [20]. A normalised overstress $\Delta \hat{\sigma}$ is defined in the following manner :

$$
\Delta \hat{\sigma}=\frac{\hat{\delta}}{\left(r-\frac{r}{S_{v}}\right)}
$$

$\hat{\delta}$ and $\mathrm{r}$ are shown in Figure 2. The viscoplastic response is then given by :

$$
\begin{aligned}
& \dot{\varepsilon}_{\mathrm{ij}}^{\mathrm{v}}=\langle\phi\rangle \frac{\partial \mathrm{F}}{\partial \tilde{\sigma}_{\mathrm{ij}}} \\
& \dot{\mathrm{e}}^{\mathbf{v}}=-\left(1+\mathrm{e}_{\mathrm{in}}\right) \dot{\varepsilon}_{\mathrm{kk} \mathbf{k}}^{\mathbf{v}}
\end{aligned}
$$

where $\phi$ represents a proper scalar function of $\Delta \hat{\sigma}$. The following form of $\phi$ has been used: 
$\phi=\frac{1}{\hat{V}}(\Delta \hat{\sigma})^{\mathrm{n}}$ if $\Delta \hat{\sigma}>0$

$\phi=0 \quad$ if $\Delta \hat{\sigma} \leq 0$

In fact, for stress state points associated with the condition $\delta>r / S_{v}$, (i.e., the stress state points situated within the elastic nucleus for viscoplastic response, ENI in Figure 2), equation (10) yields $\Delta \hat{\sigma}<0$, thus implying no viscoplastic responses.

In the above expression,

n represents a model parameter;

$\hat{\mathrm{V}}$ is a "viscosity function" and given by :

$\hat{\mathrm{V}}=\mathrm{V}\left\{\exp \left[\frac{-\mathrm{J}}{\mathrm{NI}}\right]\right\}=\mathrm{V}\left\{\exp \left[\frac{-\mathrm{q}}{\mathrm{Mp}}\right]\right\}$

where $V$ is a parameter of model. The parameter $N\left(=\frac{M}{3 \sqrt{3}}\right)$, which is a function of $\alpha$, defines the slope of critical state line (CSL) in stress invariants space. M represents the slope of CSL in stress space $\mathrm{p}$ - $\mathrm{q}$ with

$p=\frac{I}{3}, q= \pm \sqrt{3}$

\section{The plastic response}

It is given by :

$\dot{\varepsilon}_{i j}^{p}=\langle L\rangle \frac{\partial F}{\partial \bar{\sigma}_{i j}}$

$\dot{e}^{p}=-\left(1+e_{i n}\right) \dot{\varepsilon}_{k k}^{p k}$

where the loading index is defined by :

$L=\frac{1}{K_{p}}\left\{\left(F_{l}\right) \dot{I}+\left(F_{\bar{J}}\right) \dot{j}+\frac{1}{b}\left(F_{\alpha}\right) \dot{\alpha}-\langle\phi\rangle \bar{K}_{p}\left[\frac{1}{b}-c\left(1-\frac{1}{b}\right) \frac{F_{I}}{F_{L_{0}}}\right]\right\}$ 
The partial derivative with respect to an invariant is denoted with a comma followed by the symbol of the invariant as a subscript.

This expression for $\mathrm{L}$ shows the coupling between plastic and viscoplastic hardening for states on and within the bounding surface. The plastic modulus $K_{p}$ has been presented before and the bounding plastic modulus $\bar{K}_{p}$ can be obtained by :

$\bar{K}_{\mathrm{p}}=\frac{-3\left(1+e_{i n}\right)}{\lambda-\kappa}\left(\left\langle I_{0}-I_{1}\right\rangle+I_{1}\right) F_{I_{I}} F_{I_{0}}$

where $\lambda, \kappa$ are the slopes of virgin consolidation and swell/recompression lines in (e-ln p) space. $l_{i}$ represents a transitional mean normal stress at which a consolidation curve changes from linear in (e-ln p) space to linear in (e - p) space. It was introduced into the formulation to avoid the numerical errors when $I \rightarrow 0$ (resulting from excessive material softening) or $I_{0} \rightarrow>0$ (during a dilatational process for which the bounding surface contracts). $e_{\text {in }}$ represents the initial void ratio.

\section{The hardening rule}

The bounding surface is assumed to undergo isotropic hardening. The hardening is controlled by a single internal variable $e^{i}$ given by :

$$
\begin{aligned}
\dot{\mathrm{e}}^{\mathrm{i}} & =-\left(1+\mathrm{e}_{\mathrm{in}}\right) \dot{\varepsilon}_{\mathrm{kk}}^{\mathrm{i}} \\
& =-\left(1+\mathrm{e}_{\mathrm{in}}\right)\left(\dot{\varepsilon}_{\mathrm{kk}}^{\mathrm{j}}+\dot{\varepsilon}_{\mathrm{kk}}^{\mathrm{v}}\right)
\end{aligned}
$$

The evolution of the bounding surface is related to the value of $\mathrm{L}_{0}$ (Fig.2), it follows that :

$$
\frac{\mathrm{dI}_{0}}{\mathrm{de}^{i}}=-\frac{\left\langle\mathrm{I}_{0}-\mathrm{I}_{\mathrm{I}}\right\rangle+\mathrm{I}_{\mathrm{I}}}{\lambda-k}
$$

substituting (17) in (18), we have finally :

$$
\mathrm{dI}_{\mathrm{o}}=\frac{\left\langle\mathrm{I}_{0}-\mathrm{I}_{1}>+\mathrm{I}_{1}\right.}{\lambda-x}\left(1+\mathrm{e}_{\mathrm{iv}}\right) \mathrm{d} \varepsilon_{\mathrm{kk}}^{\mathrm{i}}
$$

It is noted that :

if $\mathrm{d} \varepsilon_{\mathrm{kk}}^{\mathrm{i}}>0, \mathrm{dI}_{\mathrm{o}}>0$, the material undergoes "hardening"

if $\mathrm{d} \varepsilon_{\mathrm{kk}}^{\mathrm{i}}<0, \mathrm{dl}_{\mathrm{o}}<0$, the material undergoes "softening". 
After suitable manipulation, the constitutive relations in reverse form can be written as:

$\dot{\sigma}_{i j}=D_{i j k \mid} \dot{\varepsilon}_{k j}-V_{i j}$

For integrating the constitutive relations, we have chosen the so-called method " $\theta$ point method". To obtain more accurate results, the integration time step $\Delta t$ is divided into $N$ substeps $d t$. The sub-steps size, computed as the strain increment $\Delta \|$, is constant and chosen by user.

For each sub-time step $d t$, integration of Eqs (20) and (17) are expressed as

$\sigma_{i j}(I+\theta d t)=\sigma_{i j}(I)+\dot{\sigma}_{i j}(I) \cdot \theta d t$

$\dot{\mathrm{e}}^{\mathrm{i}}(\mathrm{I}+\theta \mathrm{dt})=\dot{\mathrm{e}}^{\mathrm{i}}(\mathrm{I})+\dot{\mathrm{e}}^{\mathrm{i}}(\mathrm{I}) \cdot \theta \mathrm{dt}$

$\sigma_{i j}(I+1)=\sigma_{i j}(I)+\dot{\sigma}_{i j}(I+\theta d t) \cdot d t$

$\dot{e}^{i}(I+1)=\dot{e}^{i}(I)+\dot{e}^{i}(1+\theta d t) . d t$

where

I denotes the sub-time step number

$\theta$ is a numerical parameter which takes the value between 0 and 1 . Usually, we take $\theta>0.5$ for the reason of numerical stability.

To have a clear outlook on the meaning of model parameters, we make a brief outline of them in Table 1. 
TABLE 1 The Meaning of the Model Parameters

\begin{tabular}{|c|c|c|c|}
\hline Signification & & Symbol & Definition \\
\hline \multirow{15}{*}{$\begin{array}{l}\text { Elasto-plastic } \\
\text { parameters }\end{array}$} & \multirow{6}{*}{$\begin{array}{l}\text { Traditional } \\
\text { parameters }\end{array}$} & $\lambda$ & The slope of the virgin consolidation line in e-lnp \\
\hline & & $\kappa$ & The slope of the swell/recompression line in e-lnp \\
\hline & & $\mathbf{M}_{\mathbf{c}}$ & The slope of the critical state line in compression \\
\hline & & $\mathbf{M}_{\mathbf{e}}$ & The slope of the critical state line in extension \\
\hline & & Gor $p$ & Elastic shear modulus or Poisson's ratio \\
\hline & & $I_{1}\left(P_{a}\right)$ & A numerical parameter \\
\hline & \multirow{7}{*}{$\begin{array}{l}\text { Surface } \\
\text { configuration } \\
\text { parameters }\end{array}$} & $\mathbf{R}_{\mathbf{c}}$ & \multirow{2}{*}{$\begin{array}{l}\text { Defines the ratio of the major to minor axes of ellipse } \\
\left(\mathbf{R}_{\mathbf{c}}: \text { in compression, } \mathbf{R}_{\mathrm{e}}: \text { in extension) }\right.\end{array}$} \\
\hline & & Re. & \\
\hline & & Ac & \multirow{2}{*}{$\begin{array}{l}\text { Controls the shape of the hyperbola } \\
\left(A_{c} \text { in compression } A_{e} \text { in extension) }\right.\end{array}$} \\
\hline & & Ae. & \\
\hline & & $\mathbf{T}$ & Controls the size of ellipse 2 \\
\hline & & $S_{\mathbf{n}}$ & Elastic zone parameter related to plasticity \\
\hline & & C & Defines the projection center along Z-axis \\
\hline & \multirow{2}{*}{$\begin{array}{l}\text { Hardening } \\
\text { parameters }\end{array}$} & $\mathbf{m}$ & \multirow[t]{2}{*}{ Control the degree of plastic hardening (or softening) } \\
\hline & & $\mathbf{h}_{\mathbf{c}}$ & \\
\hline \multirow{2}{*}{\multicolumn{2}{|c|}{$\begin{array}{l}\text { Viscoplastic } \\
\text { parameters }\end{array}$}} & $\mathbf{S}_{\mathbf{y}}$ & Elastic zone parameter related to viscosity \\
\hline & & $\mathbf{V}$ & $\begin{array}{l}\text { Parameters introduced in the formulations to } \\
\text { calculate the viscoplastic responses }\end{array}$ \\
\hline \multirow{2}{*}{\multicolumn{2}{|c|}{$\begin{array}{l}\text { Initial state } \\
\text { parameters }\end{array}$}} & Gin. & Initial void ratio \\
\hline & & $\mathbf{P}_{\mathbf{c}}$ & Preconsolidation pressure \\
\hline
\end{tabular}

\section{IDENTIFICATION OF THE PARAMETERS}

To our knowledge, the Dafatias-Kaliakin model has been used with parameters identified from laboratory tests $[12,19]$ such as oedometric tests, triaxial tests and creep tests, as far as the viscoplastic parameters are concerned. In this paper, the will is to use in-situ tests rather than laboratory tests Indeed, the laboratory tests in our possession are not conclusive and 
cannot be performed again, so the preference is given to the in-situ tests [11]. Nevertheless, some parameters can only be determined from laboratory tests whereas others can be identified either from laboratory or in-situ tests. It is why the parameters are classified in four categories, as showed in Table 2. The first one concerns the parameters that are encountered in a CamClay basic model: they are called, in this paper, "Cam-Clay parameters". They are determined directly from classical laboratory tests data. The second category inchudes the other elastoplastic parameters which do not influence the viscous soil behavior. They are obtained by identification from laboratory tests and called, in the following, "elastoplastic parameters". The third category relates to the viscous parameters or the parameters which highly influence the viscous behavior. Those parameters are presented here as the "viscoplastic parameters". They are identified with the Diflupress L.D. test. This part of the identification is made difficult by the fact that the modelling of the Diflupress L.D. is indeed a boundary value problem. The Diflupress L.D. is not an homogeneous test and the followed stress paths are not as simple as the one followed in a triaxial test.

After all, the Dafalias-Kaliakin constitutive equations use effective stresses, as usual. With the finite element code used (LAGAMINE, $[17,21]$ ) it was possible to do a simulation with coupling between the mechanical law and the Darcy law. In the case of the Diflupress L.D. modelling, it is necessary to introduce a new parameter, the permeability since the test is performed under the level of the phreatic line. This parameter is determined from the classical laboratory method used to evaluate the permeability of soil.

\section{TABLE 2 Model Parameters}

\begin{tabular}{|c|c|}
\hline Parameter & \\
\hline $\begin{array}{c}\lambda, x, M_{\mathrm{c}}, \mathrm{G} \text { or } \nu, \\
\mathrm{e}_{\mathrm{in},} \mathrm{I}_{\mathrm{o}}\end{array}$ & $\begin{array}{c}\text { "Cam-Clay parameters". Determination from } \\
\text { laboratory tests. }\end{array}$ \\
\hline $\begin{array}{c}M_{e} A_{c}, A_{e}, T, S_{p} \\
C, h_{c}, h_{e}\end{array}$ & $\begin{array}{c}\text { "Elastoplastic parameters". Identification from } \\
\text { laboratory tests. }\end{array}$ \\
\hline $\mathbf{R}_{\mathbf{c}}, \mathbf{R}_{\mathbf{e}}, \mathbf{n}, \mathbf{S}_{\mathbf{v}}, \mathbf{V}$ & $\begin{array}{l}\text { "Viscoplastic parameters". Identification from } \\
\text { Diflupress L.D. in-situ tests data. }\end{array}$ \\
\hline permeability $\mathbf{k}$ & Determination from laboratory tests. \\
\hline
\end{tabular}

This paper presents a work made about the nuclear plant site of St-Laurent -des-Eaux in 
France. A campaign with the Diflupress L.D. apparatus was made on this site in 1989. At this time, few laboratory tests were performed on samples extracted close to the implantation of the tests done with the Diflupress L.D. Those laboratory tests present some contradictory results so it was decided to check the data of this campaign with the laboratory tests data performed during a previous campaign, in 1978, before the beginning of the nuclear plant construction. For this campaign, the experimental curves are not in our possession, only mean values for the geotechnical characteristics are given. So for the parameters identification, only the experimental curves from the campaign of 1989 could be used. For the determination of the "Cam-Clay parameters", a comparative study was made between the results of the two campaigns. When contradictory data were encountered, a preference was given to the first campaign (1978) because the samples and tests performed were more numerous.

In the following, the values kept for the "Cam-Clay parameters" are justified. The "elastoplastic parameters" and their influence on the response of the model are presented. One of the "viscoplastic parameters" greatly influences the response of the model under triaxial solicitation. It is $\mathbf{R}_{\mathbf{c}}$. But the adequate value for the Diflupress modelling is different from the one for the triaxial modelling. So the set of parameters for the triaxial tests and the influence of a variation of $R_{c}$ are presented in the third section. Finally, the set of parameters identified from the Difhupress L.D. modelling is presented, as well as some choices made for the modelling.

The Diflupress L.D. test is modelled by an horizontal soil section which radius is about 3 meters long. A study of sensitivity made on the size of the concerned soil mesh showed that the radius we chose is acceptable [11]. All the results presented in this paper are obtained with this reference mesh. Furthermore, the assumption of axisymetric state is made and in the direction of the axisymetric axis, plane strain is considered (zero vertical strain). At the external radius of the mesh, the nodes are blocked (zero displacements).

\section{"Cam-Clay Parameters"}

Two laboratory tests are required to evaluate the "Cam-Clay parameters". $\lambda$ and $k$, the slopes of virgin consolidation and swell/recompression lines in (e-ln p) space are determined by oedometric tests. $C_{c}$ and $C_{g}$ have the same signification than $\lambda$ and $x$ respectively but in that case, the oedometric curves are drawn in a $(e-\log p)$ diagram.

The friction angle $\phi$ (or the slope of the critical state line $M$ in the diagram (p-q)) is given by triaxial tests in compression.

The Poisson's ratio is calculated from the curves of volumetric strain versus the axial strain, obtained from triaxial tests data. 
The values of $\lambda$ (or $C_{c}$ ) are rather scattered and vary from 0.0525 to 0.181 (or 0.121 to 0.417). Data obtained from tests performed before the construction of the nuclear plant give a value of $\lambda$ varying between $0.0434(0.10)$ and $0.065(0.15)$. Faced with all theses different values, we preferred to obtain $\lambda$ from empirical expressions with the liquid limit of Atterberg, such as the following one: $C_{c}=0.007\left(w_{L}-7\right)$. This expression is validated for remoulded clays and was proposed by Azzouz et al. [22]. The mean value obtained from this empirical expression is 0.3 for $C_{c}$ (which corresponds to 0.130 for $\lambda$ ). In the following, this vahe is kept for all the calculations with the model. The values of $k$ (or $C_{g}$ ) are also scattered but cannot be compared with the ones obtained before the construction. It is usual to suppose the vahe of $x$ represents 5 to $10 \%$ of the value of $\lambda$. It would be 0.013 in our case. But, by analogy with other soils, a value of 0.0217 (which corresponds to 0.05 for $C_{g}$ ) is taken. However numerical experiments [15] show that this parameter has a small influence on the results of the Diflupress and triaxial modelling.

From the oedometric tests, the initial preconsolidation pressure is also determined. This value is necessary since it establishes the initial intersection of the bounding surface with the positive $I$ axis $\left(I_{0}\right) . I_{0}$ is a state variable which evolves with the hardening rule. The preconsolidation pressure, as for $\lambda$ and $k$, presents values scattered between 90 and $2000 \mathrm{kPa}$. These two extreme vahues are not representative. The mean value, except the extreme values, is about $130 \mathrm{kPa}$. The tests data before the construction give a mean value of $500-600 \mathrm{kPa}$. They are more numerous and the mean value is more representative so a value of $500 \mathrm{kPa}$ is kept for the preconsolidation pressure $\left(I_{0}=1500 \mathrm{kPa}\right)$.

An essential parameter of the model is the slope of the critical state line in the $(p-q)$ diagram. The critical state line highly influences the shape of the bounding surface. This parameter is called $M_{c}$ in compression and is directly related to the friction angle $\phi_{c}$ by the following expression:

$$
M_{\mathbf{c}}=\frac{6 \sin \phi_{c}}{3-\sin \phi_{c}}
$$

The friction angle $\phi_{c}$ is calculated from the value of $q$ at rupture. From a sample to another, $\phi_{\mathrm{c}}$ varies, so only the sample the depth of which is the closest to the Diflupress L.D one is considered. The three triaxial tests give, for this sample, a friction angle of about $55^{\circ}$. This value is too important for the considered clay. The first two triaxial tests correspond to overconsolidated samples. The preference is given to the test which corresponds to a sample normally consolidated. The friction angle is taken equal to $37^{\circ}$ and the value of $\mathrm{M}_{\mathrm{c}}$ is then 1.5. The value of $37^{\circ}$ is still important, in comparison with the friction angle $\left(33^{\circ}\right)$ obtained from the tests performed before the construction of the nuclear plant. 
Finally, the Poisson's ratio is determined from the curves of volumetric strain versus the axial strain given by triaxial tests data. From all the results, the values are quite scattered and a value of 0.3 is held that corresponds to the triaxial test normally consolidated at the depth of the Diflupress L.D.

\section{"Elastoplastic Parameters"}

In this section, the other "elastoplastic parameters" are presented. In the Dafalias-Kaliakin model, there are parameters in extension determined or identified from extension tests. Unfortunately, the tests in extension are unusual so the extension values of the parameters are fixed.

The first elastoplastic extension parameter is the slope of the critical state line in the (p-q) diagram in extension, $M_{e}$. Without any extension tests data, the ratio between $M_{e}$ and $M_{c}$ is taken equal to 0.95 . Since we do not have any extension tests data, the complete identification of a tridimensional model is not possible. Nevertheless, all the identification of parameters is performed with this value because a numerical study showed the stress path followed near the Diflupress probe is very close to the compression line. Furthermore, a variation of the ratio $\mathbf{M}_{\mathbf{e}} / \mathrm{M}_{\mathrm{c}}$ with a decrease of $\mathrm{M}_{\mathrm{e}}$ keeps the stress path close to the compression ( $\mathrm{Cf}$. $\S$ Infuence of Some Elastoplastic Parameters).

The "elastoplastic parameters" which do not influence the viscoplastic response are $S_{p}, C$, $A_{c}, A_{c} T, h_{c}$ and $h_{e}$ the hardening parameters. The parameter $C$ determines the projection center for the radial mapping rule. In our case, it will be kept fixed to the default value of zero [12]. The parameter $S_{p}$ determines the size of the elastic nucleus for the elastic response of the model. Its value will be kept fixed to the default value of 2 [12]. The parameters $A_{c}, A_{e}, T$ determine the shape of the bounding surface which corresponds to the soil behavior in the overconsolidated domain. This part of the surface is made of an ellipse and an hyperbola.

The parameter $A_{c}$ (and $A_{e}$ ) influences above all the response of the model for a highly overconsolidated sample, i.e. for the first triaxial test of which the confinement pressure is of $100 \mathrm{kPa}$. In the case of the tests with the Diflupress L.D., the behavior of the soil is close to one of a normally consolidated clay. So the value of $A_{c}$ is kept to its default value, i.e. 0.1 [12].

The three parameters $A_{C}, A_{c} T$ have no influence in the modelling of the Diflupress L.D. test so they are kept to the default value [12]. Finally, the hardening parameters $h_{c}$ and $h_{e}$ have no great influence on the triaxial modelling [11] but it will be seen later the value of $h_{c}$ identified from the Diflupress L.D. modelling by trial and error procedure is different from the one identified from the triaxial tests data. Indeed, a different value of $h_{c}$ allows a best fit of the 
beginning of the experimental curves obtained from the Diflupress L.D. test. But we will see later that firstly we are not sure of the beginning of the curves and secondly the most interesting part for the viscous behavior is the end of the curves. In this case, the study of sensitivity (Cf. § Influence of Some Elastoplastic Parameters) will show the parameter $h_{c}$ does not influence a lot the Diflupress L.D. modelling.

\section{Set of Parameters for the Triaxial Tests}

The set of parameters obtained after several attempts is presented in Table 3. The first part of the identification work only concerns the triaxial tests. Those laboratory tests do not involve a viscous behavior so the viscous parameters are not presented. However, the parameter $\mathbf{R}_{\mathbf{c}}$ (and $\mathbf{R}_{\boldsymbol{e}}$ ), which is classified in the "viscoplastic parameters", is firstly identified from triaxial tests data. Indeed, this parameter is essential because it determines the shape and the size of the entire bounding surface. It determines the position of the first ellipse, i.e. the part of the bounding surface that corresponds to the response of the model for a normally consolidated soil. In fact this parameter was identified first from the triaxial tests data and second from the Diflupress L.D. test. As it will be seen later, the two values of $R_{c}$ are different. In this section, the influence of $R_{c}$ on the triaxial tests modelling is shown.

TABLE 3 Set of Parameters (Set 1) Obtained by Identification from Triaxial Tests

\begin{tabular}{|l|l|l|l|l|}
\hline $\mathrm{L}_{\mathrm{o}}=1500 \mathrm{kPa}$ & $\mathrm{e}_{\mathrm{ini}}=0.9576$ & $\lambda=0.130$ & $\kappa=0.0217$ & $\mathrm{M}_{\mathrm{c}}=1.5$ \\
\hline $\mathrm{M}_{\mathrm{e}} / \mathrm{M}_{\mathrm{c}}=0.95$ & $\mathrm{R}_{\mathrm{c}}=1.5$ & $\mathrm{R}_{\mathrm{e}} / \mathrm{R}_{\mathrm{c}}=1$ & $\mathrm{~A}_{\mathrm{c}}=1.0$ & $\mathrm{~A}_{\mathrm{e}} / \mathrm{A}_{\mathrm{c}}=1$ \\
\hline $\mathrm{T}=0.1$ & $\mathrm{~S}_{\mathrm{p}}=2$ & $\mathrm{C}=0$ & $\mathrm{~h}_{\mathrm{c}}=20$ & $\mathrm{~h}_{\mathrm{e}} / \mathrm{h}_{\mathrm{c}}=1$ \\
\hline
\end{tabular}

On Figures 3 and 4 the results of the simulation of the triaxial tests for the deviator and the volumetric strain versus the axial strain are presented, with the set 1 of parameters. This set is exclusively identified from triaxial tests data. 


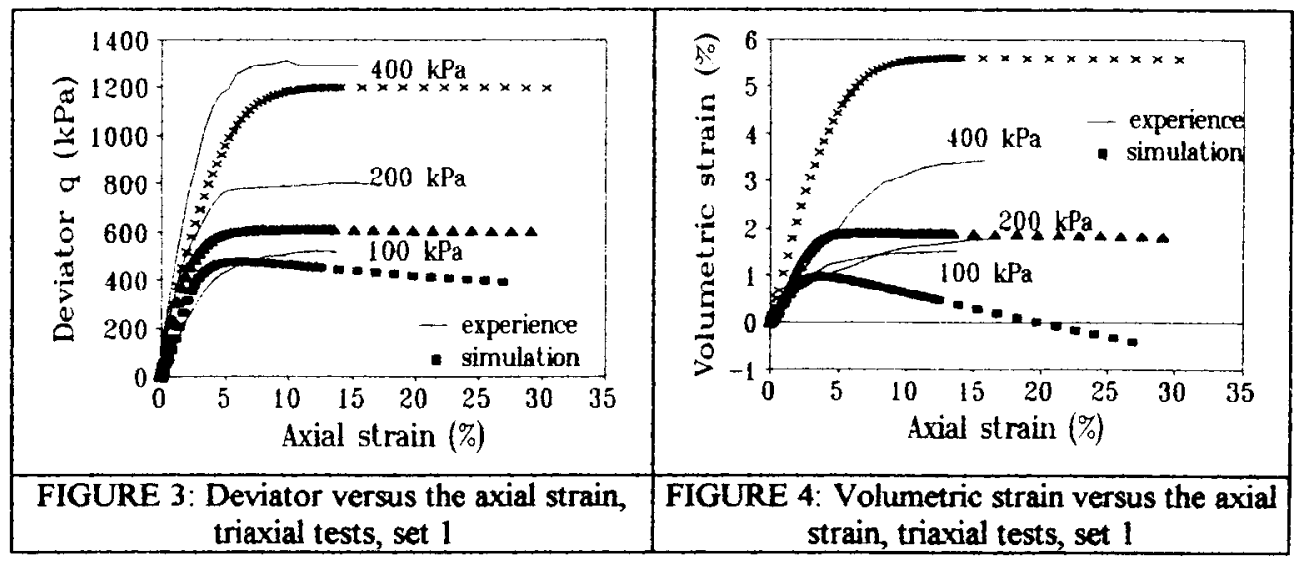

On Figures 5 and 6, the influence of small variations of $R_{c}$ is shown on the deviator and the volumetric strain versus the axial strain, for the triaxial test at $400 \mathrm{kPa}$ of confinement stress. Furthermore, when $\mathbf{R}_{\mathbf{c}}$ increases, the size of the ellipse decreases (Figure 7 . The smaller is the bounding surface, the slower the final levels of the curves of deviator or volumetric strain versus the axial strain are reached. That means that the test has to be performed longer so that the stress path cuts exactly the critical state line and the bounding surface at the same point (no more hardening, $d \varepsilon_{\mathrm{kx}}=0$ ). When there is no hardening, then the limit state of the test is reached. For the value of $\mathbf{R}_{\mathbf{c}}$ equal to 1.5 , the level for the two last triaxial tests is reached for values of axial strain close to the ones measured experimentally.

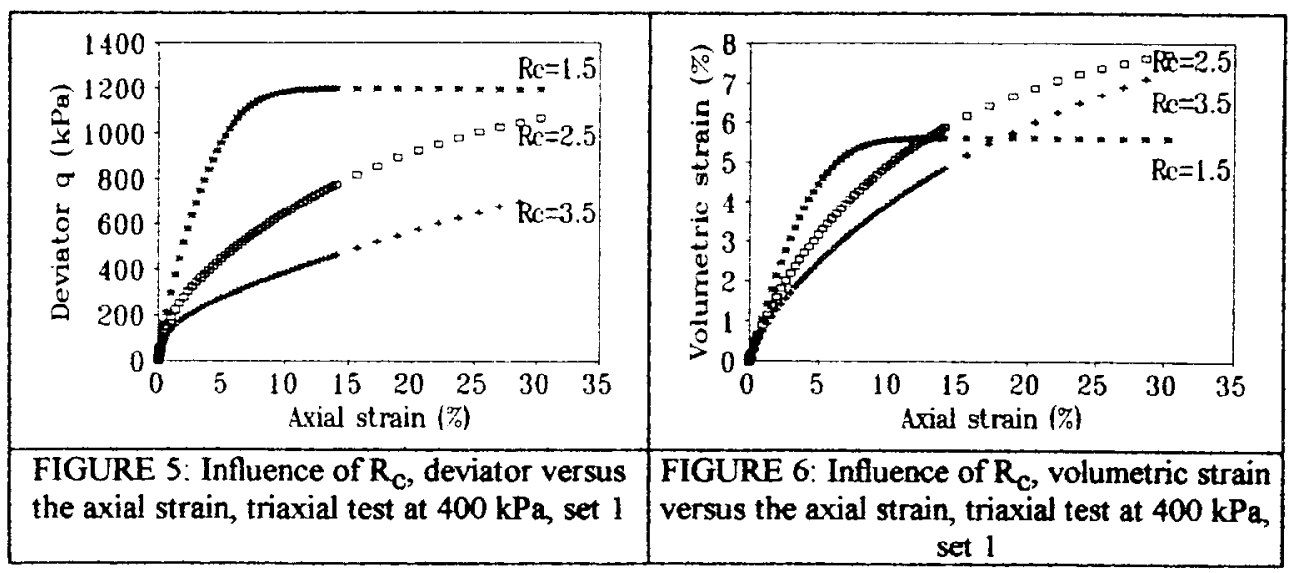

Furthermore, the elastic nucleus for the viscous response of the madel is homothetic to the bounding surface. When the bounding surface decreases, the elastic nucleus decreases as well. The distance between a stress point and the elastic nucleus varies and influences the viscous 
response of the model. This influence will be seen in the next section when identifying the viscoplastic parameters with the results of the Diflupress L.D.

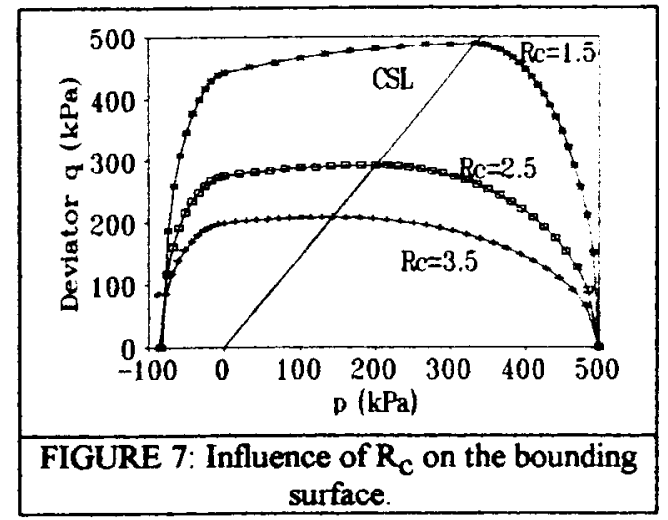

\section{"Viscoplastic Parameters"}

It was difficult to correctly identify the parameters from so few laboratory tests data. There also was some contradiction between the triaxial tests data and the Diflupress L.D. test data. To correctly model the Diflupress L.D. test, some parameters were changed, especially the parameter $\mathbf{R}_{\mathbf{c}}$ because it influences the viscous response. The use of the in-situ tests data reduces the problems of representativity of laboratory tests, remoulded or non homogeneous samples which can be encountered. As previously said, the difficulties are more important because the modelling of the Diflupress L.D. test is a boundary value problem.

The set of parameters presented in Table 2 does not give good results for the simulation of the Diflupress L.D. test. Faced to that problem, all the parameters were chosen to fit well with the Diflupress L.D. test data (except the "Cam-Clay parameters" aiready fixed). The new set of parameters is presented in Table 4.

This set is obtained by trial and error procedure. It is the first approach we used to identify the set of parameters. One can remark the value of the parameter $R_{c}$ is very different in the two sets of parameters. Actually, the value obtained on the basis of the in-situ data is not appropriate to fit the laboratory data. But there is a conflict between the good fitting of the laboratory data and the good simulation of the Diflupress L.D. tests. Probably, the elastoplastic part of the chosen model is not well adapted to the studied soil. Since we do not have enough laboratory data and we cannot make more experiments, the priority is given to the insitu tests data and to the modelling of the viscous behavior of soil. 
TABLE 4 Sets of Parameters Obtained by Identification from Triaxial Tests (Set 1) and from the Diflupress L.D. Test (Set 2).

\begin{tabular}{|c|c|c|c|c|c|c|}
\hline $\begin{array}{c}\text { Triaxial } \\
\text { tests }\end{array}$ & $\mathrm{l}_{\mathrm{o}}=1500 \mathrm{kPa}$ & $e_{\text {ini }}=0.9576$ & $\lambda=0.130$ & $x=0.0217$ & $\mathrm{M}_{\mathrm{c}}=1.5$ & $\mathrm{M}_{\mathrm{e}} \mathrm{M}_{\mathrm{c}}=0.95$ \\
\hline $\begin{array}{l}\text { Diflupress } \\
\text { L.D. test }\end{array}$ & $I_{0}=1500 \mathrm{kPa}$ & $\mathrm{e}_{\mathrm{ini}}=0.9576$ & $\lambda=0.130$ & $\kappa=0.0217$ & $\mathrm{M}_{\mathrm{c}}=1.5$ & $\mathrm{M}_{\mathbf{e}} / \mathrm{M}_{\mathrm{c}}=0.95$ \\
\hline $\begin{array}{c}\text { Triaxial } \\
\text { tests }\end{array}$ & $R_{c}=1.5$ & $R_{e} / R_{c}=1$ & $A_{c}=1.0$ & $A_{c} / A_{c}=1$ & $S_{p}=2$ & $\mathrm{C}=0$ \\
\hline $\begin{array}{l}\text { Diflupress } \\
\text { L.D. test }\end{array}$ & $\mathbf{R}_{c}=3$ & $R_{e} / R_{c}=1$ & $A_{c}=0.1$ & $A_{e} / A_{c}=1$ & $S_{p}=2$ & $\mathrm{C}=0$ \\
\hline $\begin{array}{c}\text { Triaxial } \\
\text { tests }\end{array}$ & $h_{c}=20$ & $T=0.1$ & $h_{c} / h_{c}=1$ & & & \\
\hline $\begin{array}{l}\text { Diflupress } \\
\text { L.D. test }\end{array}$ & $h_{c}=4$ & $\mathrm{~T}=0.1$ & $h_{e} / h_{c}=1$ & $S_{v}=2$ & $n=12$ & $\mathrm{~V}=\underset{\min }{1.10^{5}} \mathrm{kPa}$ \\
\hline
\end{tabular}

The basic principle adopted in the Diflupress L.D. tests [1] consists of performing creep tests in-situ by means of an inflatable probe, as used in a classical pressuremeter test. The innovation stands in the possibility to carry out a fully autonomous and automatic test during a very long period (several weeks or months). The pressure in the probe is applied by a gravity loading system made up of lead plates which build in a constant force on a piston by means of a pulley block. The length of the probe is of $97 \mathrm{~cm}$ and its initial diameter is of $60 \mathrm{~mm}$. The testing process is the following. The injection tap is opened: the constant gravity-induced pressure is instantly transmitted to the probe, which begins to inflate and the evolution of the injected volume with the time is recorded. Three successive levels of loading are carried out by increasing the pressure, without emptying the probe. The pressures applied to the probe, after usual corrections of inertia and hydrostatic pressure, are 400,495 and $600 \mathrm{kPa}$ On Figure 8 , the experimental loading which causes the creep is shown. It is deduced from the applied pressures by subtracting the soil pressure at rest $[3,11]$. The diagram shows that the loading is made instantareously by adding one or more lead plates. The load is sudden and presents a discontinuity. On a practical way, the equipment reacts to this sudden load so it is difficult to know what is really measured during the first minutes. The beginning of the curves can be then neglected. This point of view is reinforced by the fact the measures during the first minutes are taken manually. A lot of measures have to be made at the same time and the lecture can be imprecise. 
On Figures 9, 10 and 11, the experimental and numerical curves for the three levels of loading of the Diflupress L.D. test are presented. The shape of the experimental curves varies between the first level of loading and the two other levels. The change of shape of the experimental response was not explained. The Dafalias-Kaliakin model reproduces the shape of the first step for the three loading steps.

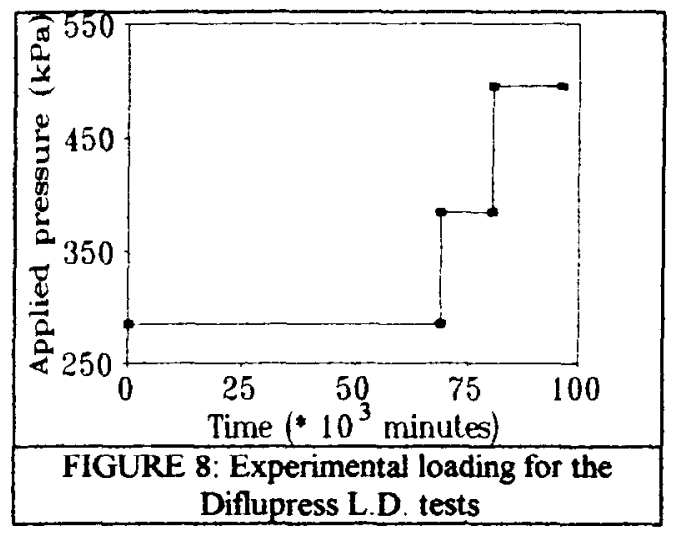

The simulated loading is quite different from the experimental loading. It is simulated by a gradual increase of the load on a finite duration. In the modelling, the loading is then simulated by a finite rate whereas the experimental loading is sudden. This choice is made in order to avoid any problem of convergence. A study on the influence of the rate of loading shows the second part of the curves is not modified [11].

Since

- the experimental measures in the first minutes are rather imprecise,

- the logarithmic scale dilates the first minutes of the tests whereas they present a small part of the total duration of the test,

- the mumerical rate of loading does not influence the second part of the curves,

- the important point in the simulation is to approach as best as possible the slopes of the second part of the curves since this second part corresponds to the creep part of the soil behavior,

the first part of the numerical and experimental curves is omitted (Figures 12 to 14).

The part of the curves presented corresponds to a constant load. 


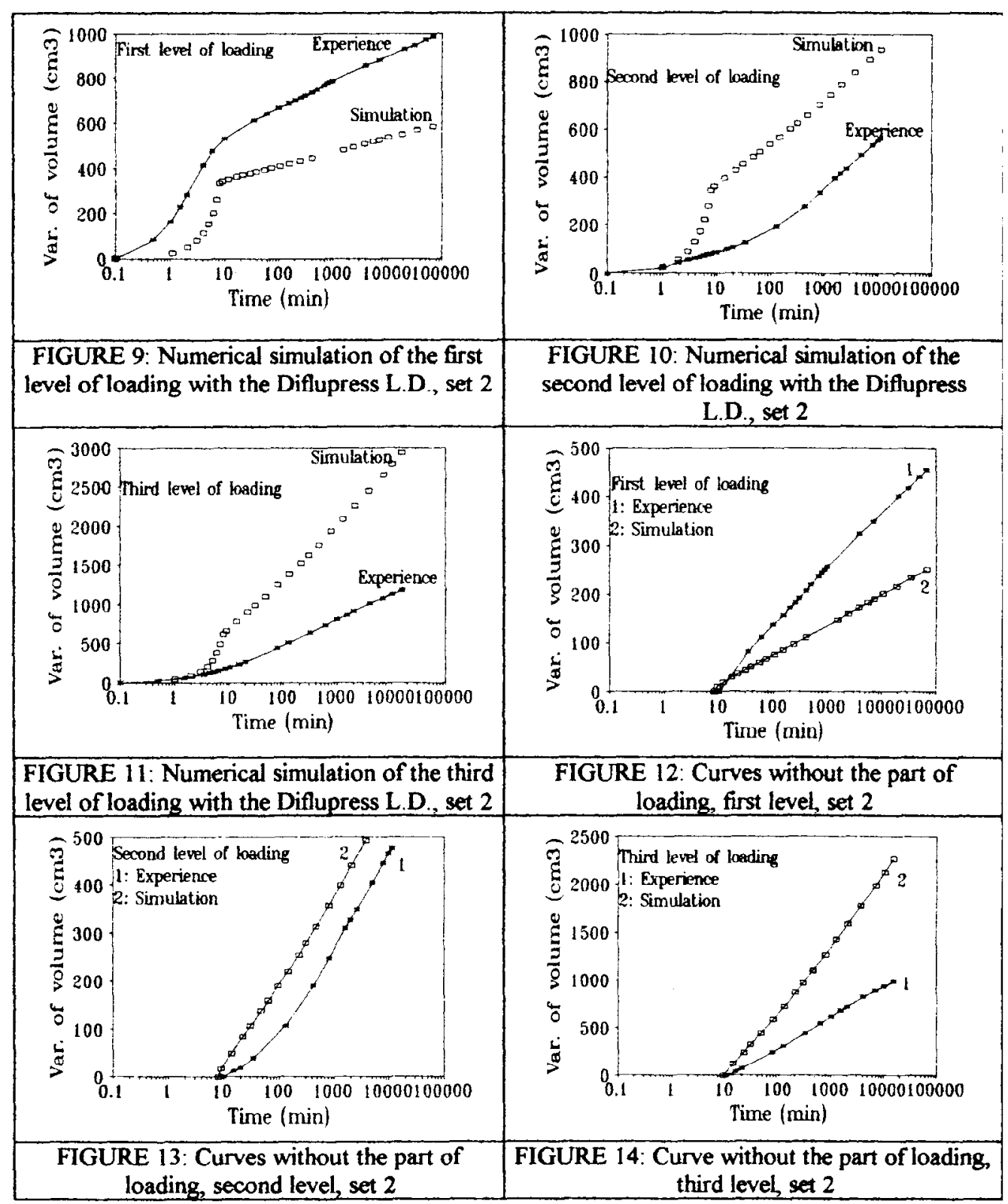

It is rather difficult to fit the three experimental curves with the same set of parameters. For the first curve, the reason of replacing the soil can be evoked. For the last curve, the difficulty can result of the fact the applied stress is relatively close to the limit pressure of the soil at this depth. A numerical simulation of a classical pressuremeter supports this assumption. It is the 
reasons why we chose to identify the parameters with the second curve of the Diflupress L.D. test. When studying the influence of the parameters, most of the time the results obtained for the second level of loading will be presented.

\section{STUDY OF SENSITIVITY}

The shape of the experimental curves can be shared in two parts, as said previously. The second part can be approached by a straight line in the logarithmic scale. It is possible to evaluate, for each experimental curve, the slope of the approached straight line. This slope is expressed in $\mathrm{cm}^{3}$ per decade since the curves are drawn in variation of volume versus time, in a semi-logarithmic diagram. In the same way, the numerical curves present a part which can be approached by a straight line. The numerical slope can be calculated. The influence of parameter variation may be characterised by the comparison of the experimental and numerical values of the slope of the second part of the curves, for the same time duration.

As said previously, a new parameter is introduced in the modelling of the Difhupress L.D. test, the permeability. It is experimentally determined from laboratory tests and is not precisely known so a study of sensitivity around the different possible values of permeability is made.

Starting from the set of parameters of Table 4, the parameters vary one after the other. The parameters can be shared in two groups: the "elastoplastic parameters" and the viscoplastic parameters. Since the slope of the second part of the curve is the important thing to obtain, the viscoplastic parameters are essential. However, the influence of some elastoplastic parameters is studied then the influence of the viscous parameters.

\section{Influence of Permeability}

A problem encountered is the determination of the permeability. The measure of permeability for the nuclear site was made with laboratory tests and the value varies between $10^{-6} \mathrm{~m} / \mathrm{s}$ and $10^{-10} \mathrm{~m} / \mathrm{s}$. So the influence of the variation of permeability was studied by performing calculations with three values of permeability $\left(10^{-6}, 10^{-8}\right.$ and $\left.10^{-10} \mathrm{~m} / \mathrm{s}\right)$. The results of the simulation are presented on Figures 15 to 17 . The higher is the permeability, the faster the second part of the curve (creep part) is reached. Furthermore, for the permeability of $10^{-10} \mathrm{~m} / \mathrm{s}$, the quasi linear part of the curves is reached at the end of the experimental time. This calculation allows the validation of the Diflupress L.D.: for the assumed permeability of the soil, the duration of the test is sufficient. On the contrary, if the permeability of soil was of $10^{-10} \mathrm{~m} / \mathrm{s}$, the duration of the tests with the Diflupress should be larger. 

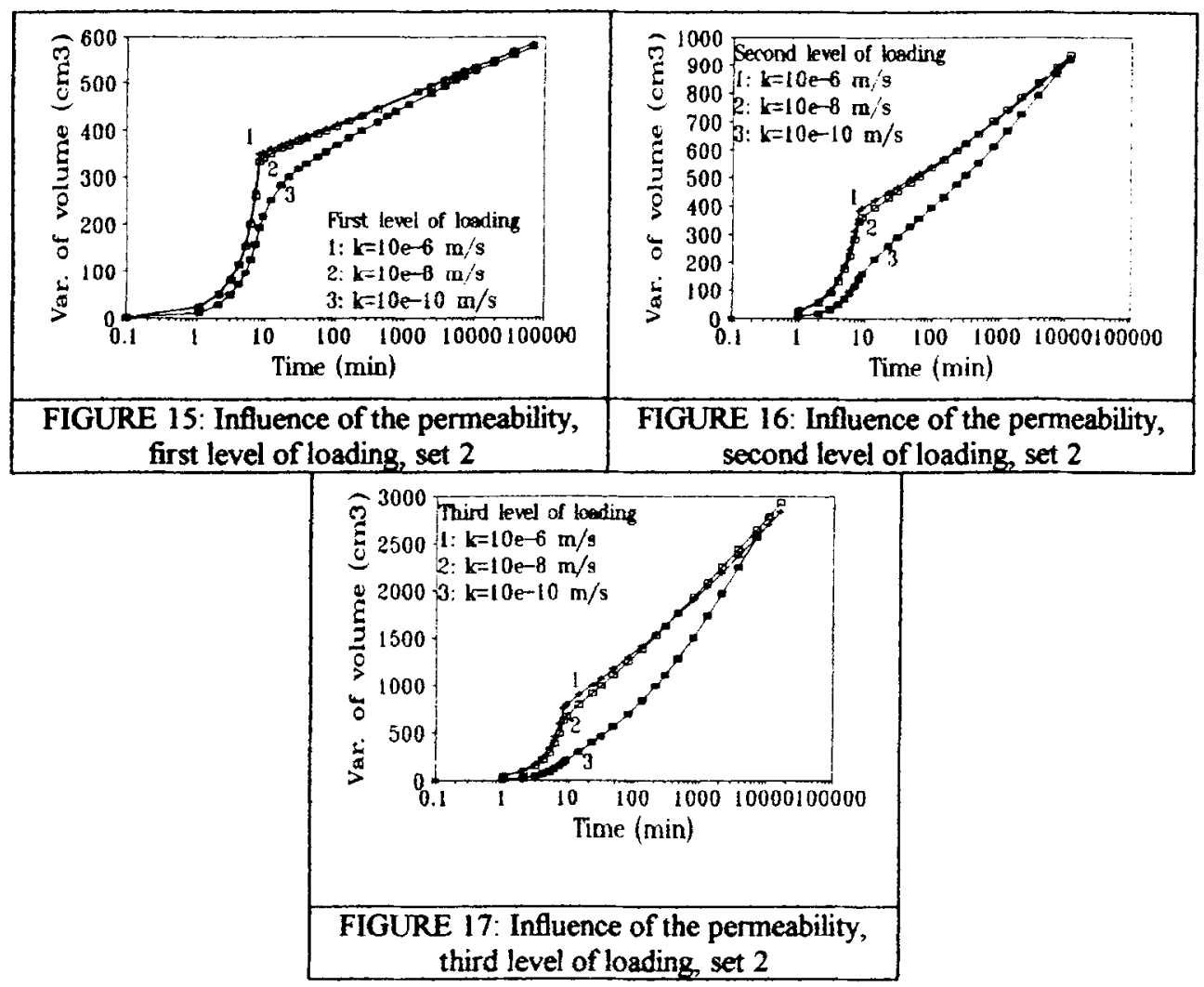

\section{Influence of Some Elastoplastic Parameters}

The essential part of the curves of the Diflupress L.D. test is the second part of the curves, that presents a shape close to a line. A best approach of the slope of the second part of the curves is then required. Then, when studying the influence of parameters on the simulation of triaxial tests, it appears that several of them are influent for samples highly overconsolidated For the Diflupress L.D. test, the soil is slightly overconsolidated, indeed normally consolidated. So we choose not to modify those parameters since they do not influence the response of a normally consolidated soil. Since the "Cam-Clay parameters" are fixed from laboratory tests data, there are few elastoplastic parameters to modify. The parameter $\mathrm{C}$ which determines the center of projection for the radial mapping rule is fixed to zero because its variation only influences the response of soils overconsolidated. The parameter $S_{p}$ which determines the size of the elastic nucleus for the plastic response is also fixed because its variation only influences the beginning of the loading, when the stress points are into the elastic nucleus. As a matter of fact, the influence of the hardening parameter $h_{c}$ and the influence of the ratio between $M_{e}$ and 
$\mathrm{M}_{\mathrm{c}}$ are tested.

Previously, the parameter $\mathrm{M}_{\mathbf{e}}$ was said very high for the soil considered. But its value was taken without any information on its possible value in extension. So a calculation with a different value of the ratio between $M_{c}$ and $M_{e}$ was performed ( 0.80 instead of 0.95$)$. When decreasing the value of the friction angle in extension, the slope of the second part of the curve is increased, that is not the wanted effect (Figure 18). Furthermore, the study of the stress path in the deviatoric plane, for a stress point close to the Diflupress probe, shows that the difference between the two paths is not important (Figure 19) and the stress path is always very close to the compression phase. Even if the value of the friction angie in extension is very high, all the identification will be performed with this value (ratio $M_{e} M_{c}$ equal to 0.95) because the stress path is still close to the compression phase. The set of parameters identified with this value of the ratio gives interesting results for the slope of the second part of the curves.

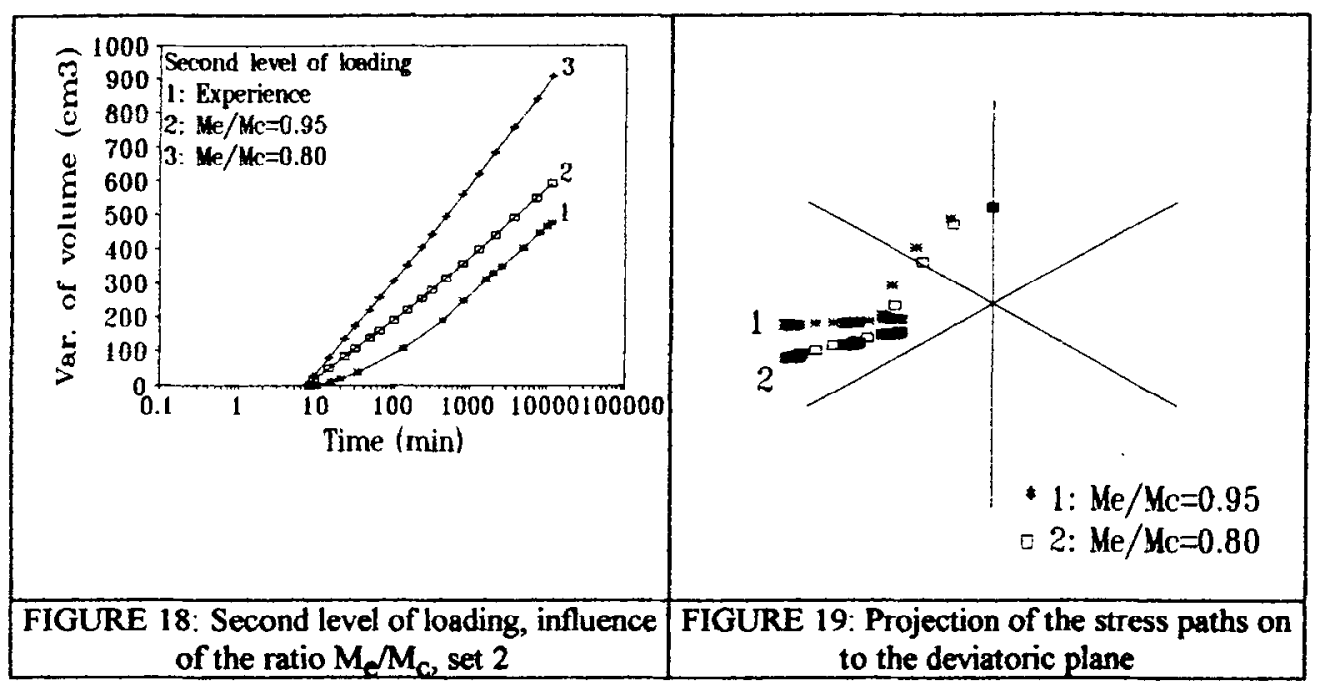

The hardening parameter $h_{c}$ is modified from its value of 4 to the value of 20 (value identified with the triaxial tests). This variation does not influence a lot the slope of the second part of the curve (Figure 20). For the second level of loading, the slope changes from $201 \mathrm{~cm}^{3}$ per decade to $222 \mathrm{~cm}^{3}$ per decade whereas the experimental slope is about $195 \mathrm{~cm}^{3}$ per decade. The default value advised by Kaliakin et al. [12] is 10 and this value will give a value for the slope between the two values previously mentioned. Finally, the hardening parameter does not really influence the second part of the curves. 


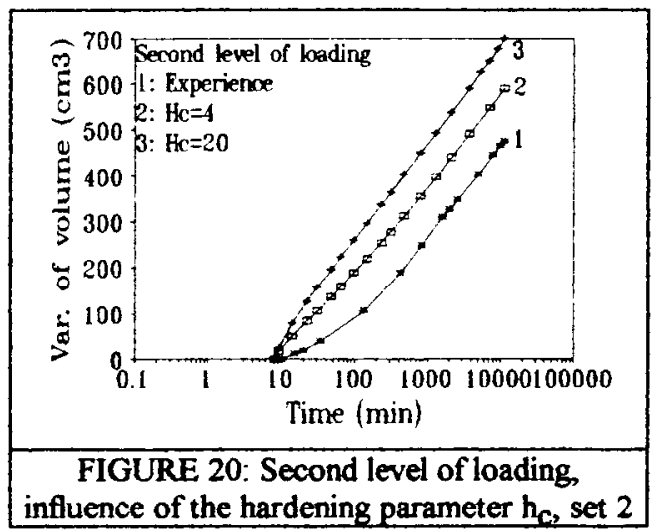

\section{Infuence of Viscoplastic Parameters}

In this part, the particular case of the parameter $\mathbf{R}_{c}$ is treated because it has a great influence on the viscous response. It was classified as a viscoplastic parameter in a large extent.

Previously with the triaxial tests, the required value for $R_{c}$ was 1.5 in order to have a important size for the bounding surface. In the case of the modelling of the Diflupress L.D., the required value for $R_{c}$ has to be more important in order to have a smaller size for the bounding surface. Indeed, on the condition that $S_{V}$ is fixed, the elastic nucleus for the calculation of the viscous response directly depends on the size of the bounding surface since it is deduced from it by homothetie. The smaller is the surface, the smaller is the nucleus and most of the real stress points can be outside the nucleus. In this case, the response of the model will be essentially viscous. The essential influence of the parameter $R_{c}$ is well ilhustrated on Figure 21 . For the value of $R_{c}$ equal to 1.5 , there is no more deformation after the loading and the creep slope of the second part of the curve is very close to zero. The viscous response of the model is non-existent. When decreasing $R_{c}$, the apparition of the viscous response is delayed. If $R_{c}$ is too small, all the stress points are into the elastic nucleus. Even if the stress path varies and the bounding surface grows by hardening, the elastic nucleus grows as well and the stress points stay into the elastic nucleus. It is clear that the shape parameter $\mathbf{R}_{c}$ has to be identified at the same time as the viscous parameters since it influences a lot the viscous response. 


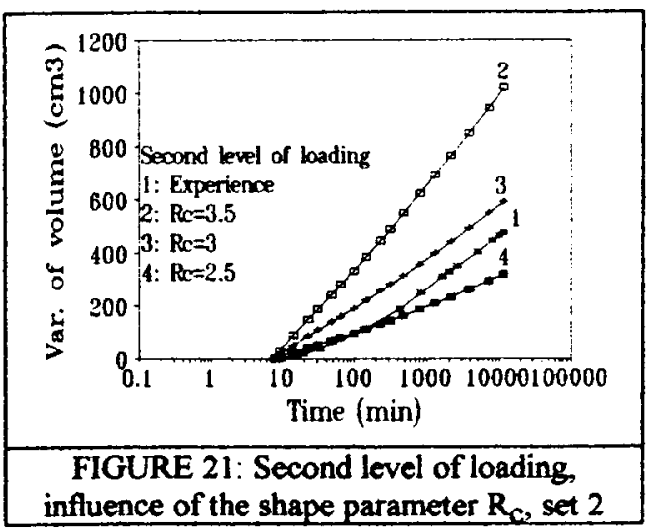

There is three other viscoplastic parameters in the Dafalias-Kaliakin model, the parameters $\mathrm{S}, \mathrm{V}$ and $\mathrm{n}$.

The first parameter $S_{\mathrm{v}}$ determines the size of the elastic nucleus for the viscous response of the model. The farthest from the elastic nucleus is the stress point, the more important is the viscous response. The size of the elastic nucleus can vary with the size of the bounding surface as said above but the size can directly vary in changing the value of $S_{v}$. When $S_{v}$ is equal to 1 , the elastic nucleus is reduced to the center of projection of the radial mapping rule. If $S_{V}$ increases, the size of the elastic nucleus also increases. The curves obtained for different values of $S_{V}$ (Figure 22) are rather close to those obtained for the variation of $R_{c}$. For a value of $S_{V}$ equal to 3 , there is no more creep slope and the viscous response disappears.

The second parameter $\mathbf{V}$ determines the viscosity function $\hat{V}$ based on the following relation $\hat{V}=V\left\{\exp \left[\frac{-J}{N I}\right]\right\}$. For the same value of the deviator, the viscosity function is more important if the parameter $\mathrm{V}$ is bigger. In this case the viscous response of the model is weaker. On the curves presented in Figure 23, a "delay" of the viscous response can be observed when $V$ increases. Nevertheless, there is always a viscous response but it is necessary to reach deviators more important in order to obtain the creep slope. If the creep slope is calculated when the "linear" part of the curves is reached, when V increases, the creep slope decreases. But for the simulation, it is important to reach the second part of the curves at the same moment as the experimental curves. Indeed, for these last ones, the creep part of the curves is rapidly reached and the value of $\mathrm{V}$ which allows to reach the creep part as rapidly is $6.10^{6} \mathrm{kPa} . \mathrm{s}$.

Finally, the last viscoplastic parameter $n$ directly influences the slope of the second part of the curves. Indeed it appears in the relation $\phi=\frac{1}{\hat{V}}(\Delta \hat{\sigma})^{n}$. $n$ influences the value of the viscous strain which depends on the position of the real stress point in relation to the elastic 
nucleus for the calculation of the viscous response. When the overstress $\Delta \hat{\sigma} \leq 0$, the viscous strain is nil. Furthermore, the overstress can be equal to a maximum of 1 (the real stress point is on the bounding surface with its "image" stress point). So when the parameter $n$ increases, the viscous strain decreases, for a same state of stress. This point is illustrated by the simulated curves presented in Figure 24. For a small variation of the value of the parameter $n$, very important variations of the value of the creep slope are noticed. In Table 5, the different values obtained for the creep slope for the variations of the parameters $\mathrm{V}$ and $\mathrm{n}$ are summarised.
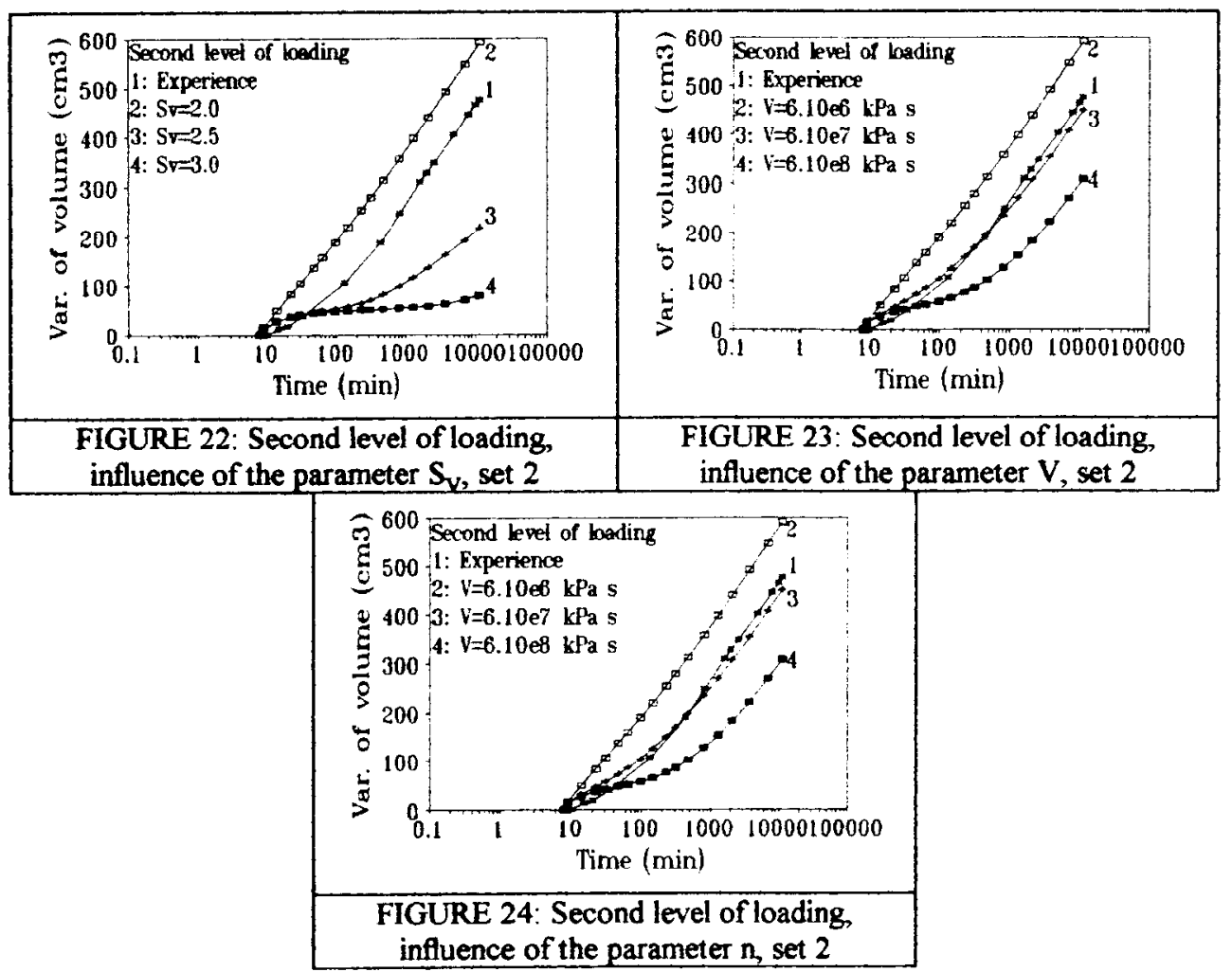

TABLE 5 Values of Creep Slope from the Variation of the Parameters V and $\mathrm{n}$, for the Second Level of Loading of the Diflupress L.D Test.

\begin{tabular}{|c|c|c|c|}
\hline parameter $\mathrm{V}$ & creep slope & parameter $\mathrm{n}$ & creep slope \\
\hline $\mathrm{V}=6.10^{6} \mathrm{kPa} . \mathrm{s}$ & $197 \mathrm{~cm}^{3} /$ decade & $\mathrm{n}=8$ & $297 \mathrm{~cm}^{3} /$ decade \\
\hline $\mathrm{V}=6.10^{7} \mathrm{kPa} . \mathrm{s}$ & $168 \mathrm{~cm}^{3} /$ decade & $\mathrm{n}=10$ & $237 \mathrm{~cm}^{3} /$ decade \\
\hline
\end{tabular}




\begin{tabular}{|c|c|c|c|}
\hline$V=6.10^{8} \mathrm{kPa} . \mathrm{s}$ & $122 \mathrm{~cm}^{3} /$ decade & $\mathrm{n}=12$ & $197 \mathrm{~cm}^{3} /$ decade \\
\hline experience & $195 \mathrm{~cm}^{3} /$ decade & experience & $195 \mathrm{~cm}^{3} /$ decade \\
\hline
\end{tabular}

The parametric analysis was made by variation of one parameter after the other. So the set of parameters obtained by this method of optimisation should not be the only set of parameters which fit well the second part of the experimental curves of the Diflupress L.D. test. As a matter of fact, Table 6 summarised the influence of the variation of the different parameters on the slope of the end of the curves. The set of parameters obtained from the study of sensitivity is not probably the only optimal set. Certainly, others set of parameters can be obtained and can present as good results as the one introduced in this paper.

TABLE 6 Influence of the Variation of Parameters on the Slope of the Second Part of the Curves of the Diflupress L.D. Test.

\begin{tabular}{|c|c|c|c|c|}
\hline & $\mathbf{M}_{\mathbf{e}} / \mathbf{M}_{\mathbf{c}}$ & $y$ & slope & $\pi$ \\
\hline & $x$ & $y$ & slope & ע \\
\hline & $h_{c}$ & त & slope & $\pi$ \\
\hline \multirow[t]{4}{*}{$\begin{array}{c}\text { Set of parameters obtained from a } \\
\text { trial and error procedure }\end{array}$} & $R_{c}$ & $y$ & slope & $y$ \\
\hline & $\mathrm{S}_{\mathrm{v}}$ & $\lambda$ & slope & $y$ \\
\hline & V & $\lambda$ & slope & $y$ \\
\hline & $\mathbf{n}$ & $\mathbf{y}$ & slope & $\pi$ \\
\hline
\end{tabular}

\section{CONCLUSIONS}

It appears that it is interesting to use in-situ test data to model practical problems with advanced constitutive equations, since the problem of remoulded samples is omitted. But the combination of parameters identified from laboratory and in-situ tests data, in the same model, is rather difficult. This paper present the first attempt of that kind, made with the DafaliasKaliakin model, to simulate the viscous behavior of natural soils.

The set of parameters obtained from laboratory and in-situ tests data is then used to simulate settlements of heavy structures $[3,11]$, whose in-situ measurements are known. The results of the simulation are encouraging. More work should be done to improve this 
approach. In Table 7, the delayed settlement obtained from the simulation is compared with the delayed settlement observed on site. The settlement curves are drawn in a semi-logarithmic diagram. The long-term settlement is linear for both curves and the slope of this linear part per $\log$ cycle is called creep slope. Since the simulation and the observation present the same shape of curve for the long-term settlement, a comparison is possible.

TABLE 7 Values of Creep Slope from the Simulated and Observed Settlement of the Foundation.

\begin{tabular}{|c|c|}
\hline & creep slope \\
\hline Simulation & $37.4 \mathrm{~mm}$ per decade \\
\hline Observation & $46.2 \mathrm{~mm}$ per decade \\
\hline
\end{tabular}

Discussions show that physic characteristics of natural soils could be determinant for the behavior of soils. For instance, some contradictions between laboratory and in-situ tests data can be due to an anisotropic structure of natural soils [23]. This could explain the differences observed between the three loading steps done with the Diflupress L.D. test. However, for the sake of simplicity, we chose to use an isotropic model for the numerical simulations.

The set of parameters presented in this paper was obtained by a trial and error procedure. In the future, a more adequate optimisation method should be used to obtain may be best sets of parameters for the numerical simulation of settlements of foundations. In the same way, a more precise parametric study should be done on the main parameters of the model which influence the viscous behavior of soils.

\section{REFERENCES}

1. G. Bufi,

New long-term pressuremeter creep test.

Proceedings of the Third International Symposium on Pressuremeters. Thomas Telford, London (1990) 95-104.

2. C. Leidwanger, E. Flavigny, J.L. Giafferi, P. Catel and G. Bufi, Delayed settlements and Diflupress L.D.

Proceedings of the Tenth International Conference on Soil Mechanics and Foundations Engineering, New-Delhi (1994).

3. C. Leidwanger, E. Flavigny, R. Chambon, J.L. Giafferi, P. Catel and G. Bufi, Application of the "Diflupress L.D." field test to settlement calculation. 
Settlement 94, ASCE Conference on Vertical and Horizontal Deformations for Foundations and Embankments, Texas A\&M University (1994)

4. B. Cambou, R. Bahar, C. Chapeau, E. Kazarian,

Numerical analysis of pressuremeter tests. Application to the identification of constitutive models.

Proceedings of the Second European Specialty on Numerical Methods in Geotechnical Engineering, Santander (1990) 369-380.

5. R. Bahar, B. Cambou, J.L. Costaz, J.J. Fry, G. Bufi and P. Catel,

Prediction of long term settlement of nuclear power plants using pressuremeter tests.

Proceedings of NUMOG IV, Vol.2 (1992) 851-859.

6. A. Asaoka and M. Matsuo,

An inverse problem approach to settlement prediction.

Soils and Foundations, $20, \mathrm{~N}^{\circ} 4$ (1980) 53-66.

7. A. Ledesma, A. Gens and E.E. Alonso, Identification of parameters in a tunnel excavation problem.

Proceedings of the Second International Symposium on Numerical Models in Geomechanics, Ghent, (1986) 333-344.

8. A. Ledesma, A. Gens and E.E. Alonso, Identification of parameters on nonlinear geotechnical models.

Proceedings of the International Conference on Computer Methods and Advancs in Geomechanics, Caims, Vol.2 (1991) 1005-1010.

9. K. Arai, H. Otha and K. Kojima,

Estimation of soil parameters based on monitored movement of subsoil under consolidation. Soils and Foundations, 24, $\mathrm{N}^{\circ} 4$ (1984) 95-108.

10. K. Arai, H. Otha and K. Kojima,

Estimation of non linear constitutive parameters based on monitored movement of subsoil under consolidation.

Soils and Foundations, 27, $N^{\circ} 1$ (1987) 35-49.

11. C. Leidwanger,

Etude des tassements différés à partir de résultats d'essais au Diflupress Longue Durée.

Thèse de doctorat, Université J. Fourier, Grenoble 1 (1993).

12. V.N. Kaliakin, Y.F. Dafalias and L.R. Herrmann,

Time Dependent Bounding Surface Model for Isotropic Cohesive Soils.

Notes for a short course, beld in conjunction with the Second International Conference on Constitutive Laws for Engineering Materials: Theory and Application, Tucson Arizona (1987).

13. Y.F. Dafalias and L.R. Hermann,

Bounding Surface Formulation of Soil Plasticity. 
Chapter 10 in: Soil Mechanics - Transient and Cyclic Loads, Ed. by G.N. Pande and O.C. Zienkiewicz,

John Wiley \& Sons Ltd. (1982).

14. V.N. Kaliakin and Y.F. Dafalias,

Theoretical Aspects of the Elastoplastic-Viscoplastic Bounding Surface Model for Cohesive Soils.

Soils and Foundations, $30, N^{\circ} 3$ (1990) 11-24.

15. L.R. Herrmann, Y.F. Dafalias, J.S. De Natale,

Bounding Surface Plasticity for Soil Modelling.

Feb. 1981, CR81.008, Dept. Civil Engineering, Report, Univ. Calif., Davis.

16. V. Kaliakin and $Y$. Dafalias,

Details regarding the elastoplastic-viscoplastic bounding surface model for isotropic cohesive soils.

Civ. Eng. Rep. ${ }^{\circ}$ 91-1, Feb. 1991, Dept. of Civil Eng., University of Delaware, Newark, DELAWARE, U.S.A.

17. R. Charlier,

Approche unifiée de quelques problèmes non linéaires de mécanique des milieux continus par la méthode des éléments finis (grandes déformations des métaux et des sols, contact unilatéral de solides, conduction thermique et écoulement en milieux poreux.

Thèse de doctorat, Université de Liège (1987).

18. X.L. Li, R. Charlier, C. Schroeder, S. Cescotto,

Evaluation et Implémentation du modèle de Dafalias-Kaliakin pour les Argiles dans un contexte de grandes déformations.

Proceedings of the International Colloque Geotechnique et Informatique, Paris (1992).

19. X.L. Li,

Contribution à la modélisation du comportement mécanique des argiles avec prise en compte de la consolidation secondaire.

Mémoire de Maîtrise, Université de Liège (1992).

20. P. Perzyna,

The Constitutive Equations for Rate Sensitive Plastic Materials.

Quarterly of Applied Mathematics, Vol. 20 (1963)

21. S. Cescotto,

General Strategy for Nonlinear Finite Element Formulation

Proceedings of the $5^{\text {th }}$ Int. Symposium on Numerical Methods in Engineering.

Ed. R. GRUBER et al., Springer Verlag, Vol. 1 (1989) 155-164.

22. A.S. Azzouz, R.J. Krizek, R.B. Corotis,

Regression analysis of soil compressibility.

Soils and Foundations, $16, N^{\circ} 2$ (1976) 19-29. 
23. S.Leroueil and P. Vaughan,

The general and congruent effects of structure in natural soils and weak rocks.

Geotechnique, 50, $N^{\circ} 3$ (1990) 467-488.

Received 4 January 1994; revised version received 25 July 1994; accepted

9 August 1994 